Article

\title{
A Nutritional-Toxicological Assessment of Antarctic Krill Oil versus Fish Oil Dietary Supplements
}

\author{
Susan M. Bengtson Nash ${ }^{1, *}$, Martin Schlabach ${ }^{2}$ and Peter D. Nichols ${ }^{3}$ \\ 1 Griffith University, Environmental Futures Research Institute, Nathan, QLD 4111, Australia \\ 2 The Norwegian Institute for Air Research (NILU), Kjeller 2027, Norway; E-Mail: msc@nilu.no \\ 3 CSIRO Food and Nutrition, Oceans and Atmosphere Flagships, GPO Box 1538, TAS 7000, \\ Australia; E-Mail: Peter.Nichols@CSIRO.au \\ * Author to whom correspondence should be addressed; E-Mail: s.bengtsonnash@griffith.edu.au; \\ Tel.: +61-737-355-062.
}

Received: 4 May 2014; in revised form: 30 June 2014 / Accepted: 7 August 2014 /

Published: 28 August 2014

\begin{abstract}
Fish oil dietary supplements and complementary medicines are pitched to play a role of increasing strategic importance in meeting daily requirements of essential nutrients, such as long-chain $\left(\geq \mathrm{C}_{20}, \mathrm{LC}\right)$ omega-3 polyunsaturated fatty acids and vitamin $\mathrm{D}$. Recently a new product category, derived from Antarctic krill, has been launched on the omega-3 nutriceutical market. Antarctic krill oil is marketed as demonstrating a greater ease of absorption due to higher phospholipid content, as being sourced through sustainable fisheries and being free of toxins and pollutants; however, limited data is available on the latter component. Persistent Organic Pollutants (POP) encompass a range of toxic, man-made contaminants that accumulate preferentially in marine ecosystems and in the lipid reserves of organisms. Extraction and concentration of fish oils therefore represents an inherent nutritional-toxicological conflict. This study aimed to provide the first quantitative comparison of the nutritional (EPA and DHA) versus the toxicological profiles of Antarctic krill oil products, relative to various fish oil categories available on the Australian market. Krill oil products were found to adhere closely to EPA and DHA manufacturer specifications and overall were ranked as containing intermediate levels of POP contaminants when compared to the other products analysed. Monitoring of the pollutant content of fish and krill oil products will become increasingly important with expanding regulatory specifications for chemical thresholds.
\end{abstract}


Keywords: Antarctic krill oil; dietary supplements; persistent organic pollutants; long-chain omega-3 polyunsaturated fatty acids

\section{Introduction}

Fish are a nutrient-dense food source. The role of marine-derived, long-chain (LC) $\left(>C_{20}\right)$ omega-3 ( $\omega 3$ ) polyunsaturated fatty acids (LC-PUFA), in the promotion of health is well established. Since early observations that Greenland Eskimos who subsisted on large amounts of fish suffered low levels of cardiovascular disease related mortality, epidemiological and experimental evidence has confidently shown the protective role of sufficient $\omega 3$ LC-PUFA intake against cardiovascular disease and certain types of cancer, e.g., [1,2]. In particular docosahexaenoic acid (DHA, 22:6w3) and eicosapentaenoic acid (EPA, 20:5 13 ), each with distinct roles in disease prevention, have been credited for their contribution to a healthy diet. In addition to serving as energy stores, $\omega 3$ LC-PUFA form integral structural components of cellular membranes [3]. For example, $\omega 3$ LC-PUFA are highly concentrated in the cellular membranes of the retina and brain and accumulate there rapidly in the third trimester of foetal development. Gestational $\omega 3$ LC-PUFA restrictive studies have shown significant deleterious impact to off-spring visual acuity and cognitive function [4]. Finally, symptomatic alleviation with $\omega 3$ LC-PUFA intake has been reported for a broad range of health conditions. Anti-inflammatory properties of $\omega 3$ LC-PUFA provide a molecular basis for symptomatic alleviation of inflammatory disease such as rheumatoid arthritis, lupus and asthma [5-7]. More recently improvements in psychiatric disorders such as depression and schizophrenia with $\omega 3$ LC-PUFA administration have been observed [8].

Fish oil is also a rich source of lipid-soluble micronutrients such as vitamin D, which plays a fundamental role in bone health [9]. Consequently, The National Heart Foundation of Australia, in accordance with a host of international agencies, recommends consumption of fish at least twice a week. Paradoxically, modern diets in developed nations are characterised by severe $\omega 3$ LC-PUFA deficiency, reflecting low seafood intake. This was exemplified in a recent study which found $78 \%$ of the Australian population did not meet their daily recommended intake of $\omega 3$ LC-PUFA [10]. In fact, it must be considered that meeting health targets for seafood intake is not economically nor ecologically attainable for large fractions of the global population [11].

Effectively tackling dietary deficiency of seafood micronutrients would carry significant bearing on both the social and economic burden of disease. Increasing the dietary status of vitamin D alone in Western Europe has been estimated to alleviate the economic burden of disease by $\$ 293$ billion per year [12]. In the absence of sufficient high quality, affordable seafood sources, dietary supplements and complementary medicines are pitched to play a role of increasing strategic importance.

A new product category has been launched on the omega-3 nutriceutical market and is currently gaining significant market share. A nutriceutical oil derived from Antarctic krill (Euphausia superba), a Euphausiid crustacean forming the basis of the Antarctic food web, has been marketed since 2002 and has recently become broadly available in Australia [13]. Marketing of krill oil centres on three characteristic properties of the oil. Krill oil contains the essential nutrient, choline and an antioxidant, 
astaxanthin. In addition, it is posed that Antarctic krill oil derived $\omega 3$ LC-PUFA is more bioavailable compared to fish oils. A higher fraction of $\omega 3$ LC-PUFA is associated with phospholipids in krill oil, compared to triacylglycerols in fish oils. This property has been theorised to improve absorption and bioavailability of $\omega 3$ LC-PUFA [14], based upon independent liposome carrier research [15]. Secondly, one major krill oil manufacturer has achieved Marine Stewardship Council certification of sustainability and, as a whole, the industry is often viewed as being sustainable due to the fact that the worldwide harvest constitutes only a minor fraction of established fishing quotas, e.g., [14,16]. It should be noted, however, that uncertainty surrounds the distribution and density of circumpolar krill stocks and therefore the robustness of fishery quotas remains debated [17]. Finally, krill oil is cited as being naturally free of toxins and pollutants [6]. Persistent Organic Pollutants (POPs) are toxic contaminants that bioaccumulate, and have been introduced to the environment since the mid-1900s. Their extreme persistence and effective environmental dispersal mechanisms have resulted in ubiquitous contamination of all environmental matrices. POPs are considered a substantial risk to human health [18] and are subject to the Stockholm Convention, a legally binding treaty signed by over 100 nations, and ratified by Australia in 2004 [19].

Within an ecosystem, lower trophic level species such as zooplankton, are often found to accumulate lower levels of POP contaminant burdens due to shorter life-spans. However, this cannot be assumed when comparing species from different ecosystems. Polar species are characterised by large body size and long life spans. Antarctic krill live to 5-7 years which is comparable to, or longer than, source species commonly used in fish oil production [13]. Similarly, Antarctic krill have demonstrated highly adaptable feeding, and in addition to their herbivorous feeding, have been observed to rely on cannibalism and detritivory to endure food deprivation [20]. This dietary flexibility also confounds their trophic placement and thus the POP bioaccumulation patterns of the species.

Historical or "legacy" POPs are chlorinated compounds. Their common molecular structures predict similar environmental behaviour. In the physical environment they are semi-volatile. Volatilized fractions will undergo progressive movement towards colder and colder climates experiencing "cold-trapping" at the poles of the earth [21]. In the particulate phase they will adhere strongly to organic matter representing an effective mechanism for transfer from the terrestrial to the aquatic environment and assimilation into food-webs. Consequently, the vast majority of human exposure to POPs occurs via seafood consumption [22,23]. This clear nutritional-toxicological conflict associated with seafood intake has urged the Codex Alimentarious Commission for Contaminants in Food to convene an expert consultancy on the risks and benefits of fish consumption [18]. In the case of fish oil dietary supplements, the scenario is even more acute. Legacy POPs are extremely lipophilic and accumulate in the fat reserves of animals. When the lipid fractions of seafood are selectively isolated and concentrated for administration as dietary supplements or complementary medicines, the seafood micronutrient:POP burden conflict is exacerbated. Indeed, repeated incidences of fish oil product recalls due to exceedance of POP safety guideline have occurred and are only likely to rise as the market expands and authorities pursue greater regulatory overview [24,25].

Recently we conducted the most comprehensive analytical survey of POPs in any Antarctic environmental matrix to date [26]. Our study centred on Antarctic krill, as POP vectors to the remainder of the Antarctic food-web, and extended across almost a quarter of the Antarctic continent. Our findings highlighted that Antarctic krill POP profiles were distinct from those typical of northern 
hemisphere species, but that they were not insubstantial. Indeed, for some compounds such as hexachlorobenzene (HCB), levels were comparable to or greater than those of similar trophic level species in other global regions. This work has prompted the following strategic examination of commercial krill oil products. Here we will assess krill oil POP burdens, as well as product nutritional lipid class and fatty acid profiles. These will be compared to those of other categories of commercial fish oil dietary supplements available on the Australian market.

\section{Experimental Section}

\subsection{Product Selection}

Four categories of seafood-oil dietary supplements were selected for analysis, namely, (i) krill oil; (ii) enriched (in terms of EPA + DHA) fish oil; (iii) nutriceutical formulations containing fish oil; and (iv) standard or budget grade 18:12 (EPA + DHA) fish oil (Table 1). Products representative of the two major krill oil manufacturers were selected under the krill oil category. For the other remaining categories, three representative and readily available brands were selected. Efforts were made to combine capsules from two separate batches of each product for each POP and FA analysis. This was achieved for all products except Blackmores Omega Liquid Fish Oil for which only a single batch number could be sourced. Full details of selected products and batch numbers are listed in Table 1.

\subsection{Sample Analysis}

\subsubsection{Lipid Extraction and Class Determination}

Pre-weighed (c.a. $0.03 \mathrm{~g}$ ) oil samples were used for lipid analyses. Individual capsule or liquid oil samples were cut open and dissolved in $\mathrm{CHCl}_{3}$. A known aliquot of total lipid (achieving a final concentration of approximately $10 \mathrm{mg}$ lipid $/ \mathrm{mL} \mathrm{CHCl}_{3}$ ) was transferred into separate vials and made up to $1.5 \mathrm{~mL}$ of $\mathrm{CHCl}_{3}$.

\subsubsection{Fatty Acid (FA) Determination}

An aliquot of the total lipid extract was trans-methylated by addition of $\mathrm{MeOH} / \mathrm{HCl} / \mathrm{CHCl}_{3}$

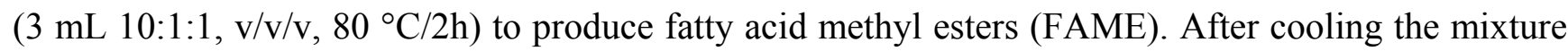
and addition of $1 \mathrm{~mL}$ of water, FAME were extracted $(3 \times)$ with 4:1 hexane/dichloromethane. A C19 FAME internal injection standard was added prior to analysis by gas chromatography (GC) using a GC (Agilent Technologies 7890A) equipped with a Supelco Equity ${ }^{\mathrm{TM}_{-}}$- fused silica capillary column (15 $\mathrm{m} \times 0.1 \mathrm{~mm}$ internal diameter, $0.1 \mu \mathrm{m}$ film thickness) [27]. GC-mass spectrometry (GC-MS) confirmed FAME identifications and was performed on a Finnigan Thermoquest GCQ GC-mass spectrometer fitted with a column of similar polarity to that described above, an on-column injector and using Thermoquest Xcalibur software (Austin, TX, USA). Helium was used as carrier gas and other operating conditions were as previously described [27]. The relative levels of individual FA were expressed as percent of total FA area. A catalogue of quantified FA is presented in Table 2. FA present at less than $0.5 \%$ of total FA in all products are grouped as Other FA; this FA group comprised $1.6 \%-4.2 \%$ of the total FA across the products analysed. 
Table 1. Selected fish and krill oil nutriceutical products compared in this study. Capsules or subsamples from two separate batches of each product were pooled for each fatty acids (FA) analysis, except for Blackmores Omega Liquid Fish Oil for which only a single batch number could be sourced.

\begin{tabular}{|c|c|c|c|}
\hline Krill Oil & Enriched Fish Oil & Formulations Containing Fish Oil & Standard 18:20 Grade Fish Oil \\
\hline & $\begin{array}{l}\text { BIO organics Super Liquid Fish Oil } \\
\text { EPA } 1.6 \mathrm{~g} \text {; DHA } 810 \mathrm{mg} \\
5 \mathrm{~mL} \text { serve } \\
\text { (Batch 11448A and 11815A) }\end{array}$ & $\begin{array}{c}\text { Blackmores Omega Joint } \\
\text { "Mercury, PCB and dioxin tested" } \\
\text { EPA } 550 \mathrm{mg} \text {; DHA } 120 \mathrm{mg} \\
1000 \mathrm{mg} \text { capsule } \\
\text { (Batch } 252505 \text { and } 252076)\end{array}$ & $\begin{array}{l}\text { Nature's Own Odourless Fish Oil } 1000 \mathrm{mg} \\
\text { EPA } 180 \mathrm{mg} \text {; DHA } 120 \mathrm{mg} \\
1000 \mathrm{mg} \text { capsule } \\
\text { (Batch } 650566 \text { and } 652769 \text { ) }\end{array}$ \\
\hline Swisse Wild Krill Oil (NKO) & Blackmores Omega Liquid Fish Oil & Nature's Way Kids Smart & Blackmores Odourless Fish Oil 1000 mg \\
\hline EPA $47 \mathrm{mg}$; DHA $28 \mathrm{mg}$ & EPA $1.7 \mathrm{~g} ;$ DHA $1.1 \mathrm{~g}$ & EPA $28 \mathrm{mg}$; DHA $133 \mathrm{mg}$ & EPA $180 \mathrm{mg}$; DHA $120 \mathrm{mg}$ \\
\hline $333 \mathrm{mg}$ capsule & $5 \mathrm{~mL}$ serve & $1000 \mathrm{mg}$ capsule & 1000 mg capsule \\
\hline (Batch 022537 and 022538) & (Batch 10709101) & (Batch B8514-1 and Batch C4401) & (Batch 252461 and 253417) \\
\hline Norkrill (Aker BioMarine) & Bioceuticals OmegaSure Liquid Fish Oil & Blackmores Pregnancy and Breastfeeding Gold & Cenovis Fish oil $1000 \mathrm{mg}$ \\
\hline EPA $60 \mathrm{mg}$; DHA 28mg & EPA $1050 \mathrm{mg}$; DHA $750 \mathrm{mg}$ & EPA $25 \mathrm{mg}$; DHA $125 \mathrm{mg}$ & EPA 180mg; DHA $120 \mathrm{mg}$ \\
\hline $500 \mathrm{mg}$ capsule & $5 \mathrm{~mL}$ serve & $1000 \mathrm{mg}$ serve & $1000 \mathrm{mg}$ capsule \\
\hline (Batch 390048 and 443003) & (Batch 26764 B L80 and 26764 C L80) & (Batch 252025 and 250973) & (Batch 650588 and 649319) \\
\hline
\end{tabular}




\subsubsection{Quality Control}

For lipid class and FA profiling, commercial (Nuchek) and laboratory standards (e.g., tuna oil) of known composition were routinely analysed to both confirm component identifications and ensure data quality.

\subsubsection{Chemical Analysis}

Oil samples were analysed for chlorobenzenes (hexa- and penta-chlorobenzene); chlorinated pesticides; hexachlorocyclohexanes $(\alpha-, \beta-, \gamma-\mathrm{HCH})$; the dichlorodiphenyltrichloroethane (DDT) group (o,p'-DDE, p,p'-DDE, o,p'-DDD, p,p'-DDD, o,p'-DDT, p,p'-DDT); toxaphene (Tox-26, 32, $40+41$, 42a, 44, 50, 62); polychlorinated cyclodienes (endosulfan-I , endosulfan-II, endosulfan-sulphate, heptachlor-exo-epoxide, heptachlor-endo-epoxide, trans-chlordane, cis-chlordane, oxychlordane, chlordene, heptachlor, trans-nonachlor, cis-nonachlor, dieldrin, aldrin, isodrin, endrin) and the individual compounds mirex and trifluralin. In addition, samples were analysed for the polychlorinated biphenyl (PCB) congeners, 18, 28, 31, 33, 37, 47, 52, 66, 74, 77, 81, 99, 101, 105, 114, 118, 122, 123, 126, 128, 138, 141, 149, 153, 156, 157, 167, 169, 170, 180, 183, 187, 189, 194, 206 and 209 (IUPAC numbers) and polychlorinated dibenzo-p-dioxin/furan (PCDD/F) congeners; 2,3,7,8-TCDD, 1,2,3,7, 8-PeCDD， 1,2,3,4,7,8-HxCDD， 1,2,3,6,7,8-HxCDD， 1,2,3,7,8,9-HxCDD， 1,2,3,4,6,7,8-HpCDD, OCDD, 2,3,7,8-TCDF, 1,2,3,7,8/1,2,3,4,8-PeCDF, 2,3,4,7,8-PeCDF, 1,2,3,4,7,8/1,2,3,4,7,9-HxCDF, 1,2,3,6,7,8-HxCDF， 1,2,3,7,8,9-HxCDF， 2,3,4,6,7,8-HxCDF， 1,2,3,4,6,7,8-HpCDF， 1,2,3,4,7,8, 9-HpCDF and OCDF.

\subsubsection{Sample Preparation and Clean-up}

The extraction and clean-up methods for POP have previously been described in full [26]. In brief, dioxin, furan and non-ortho PCB sample extraction and clean-up was performed on a semi-automated 3 column system (first column, $\mathrm{Na}_{2} \mathrm{SO}_{4}$, activated silica and potassium silicate; second column, single use Fluid Management Systems (FMS) silica column; third column, single use FMS activated carbon column). The sample portion containing PCDD/Fs and non-ortho PCBs was eluted from column 3 with toluene, reduced and exchanged to hexane before undergoing further clean-up by sulphuric acid coated silica column followed by potassium hydroxide coated silica column.

Samples for PCB and chlorinated pesticide analysis were extracted on a cold-column and cleaned by gel permeation chromatography, alumina and silica gel columns.

\subsubsection{Quantification}

The isomer identification and quantification was carried out with HRGC/HRMS using a Hewlett-Packard 5890II (1990-2003) or 6890N (2003-2006) gas chromatograph coupled to an AutoSpec mass spectrometer (Micromass Waters, Manchester, UK). Resolution of mass spectrometer was $>10,000$ with electron ionization mass spectrometry in the selected ion monitoring mode (GC/EI-HRMS-SIM). Two SIM values were monitored for each isomer group. The added ${ }^{13} \mathrm{C}$-labelled isomers were used as internal standard for each group. Additionally, the recovery rates of the added internal standard compounds were determined. 


\subsubsection{Quality Assurance}

The following quantification conditions were fulfilled for all data presented: (i) the retention time of the native compound was within three seconds of the corresponding ${ }^{13} \mathrm{C}$-labelled isomer; (ii) the isotope ratio of the two monitored masses was within $+20 \%$ of the theoretical value; (iii) the signal/noise was $>3 / 1$ for quantification; (iv) the recovery of the added ${ }^{13} \mathrm{C}$-labelled internal standards was within $40 \%$ to $120 \%$ and thereby in agreement with EU and US guidelines and official methods; (v) prior to each new series of samples the blank values of the complete clean-up and quantification procedures were determined. Clean-up of samples only commenced when a sufficiently low blank value was obtained. At least once a year the laboratory participates in an international laboratory inter-calibration exercise.

\subsection{Metrics}

\subsubsection{Tolerable Daily Intake (TDI)}

Various regulatory bodies and food authorities have assessed the levels of chemicals that are safe for human consumption, based upon observed affect levels in animal models. The tolerable daily intake (TDI) refers to a threshold of a chemical which does not appear to carry an appreciable risk. In the current study we have used a variety of sources for our reference TDIs, namely Health Canada and the US EPA, The World Health Organisation and the International Panel on Chemical Safety (IPCS) as well as peer-reviewed literature.

\subsubsection{Toxicity Equivalency Factors (TEQs)}

Toxicity equivalency factors express the toxicity of similar acting, planar, dioxin, furan and certain PCBs relative to the most potent congener 2,3,7,8-TCDD which is assigned a value of 1.0. The TEQ values applied in the current study refer to Van den Berg et al.'s 2005 re-evaluation of TEQ values [28].

\section{Results and Discussion}

\subsection{Lipid and Fatty Acid Profiles}

The majority of categories and brands of seafood oil supplements matched or exceeded manufacturer EPA and DHA specifications, with the exception of three brands which fell slightly below $(\sim 10 \%-30 \%)$ the manufacturer specifications (Tables $1-3)$. These related to EPA levels in one enriched fish oil, namely Blackmores Omega liquid fish oil (1700 mg specified vs. $1500 \mathrm{mg}$ observed) and DHA levels in Nature's Way Kidsmart (133 mg specified vs. $95 \mathrm{mg}$ observed) and Blackmores Pregnancy and Breastfeeding Gold (125 mg specified vs. $85 \mathrm{mg}$ observed). It is noted, that for pure oil capsules it is possible to compensate for EPA and DHA batch variability through marginal capsule volume adjustments. This is however, less readily achievable for formulations, such as the latter two products, and uncontrollable for liquid formulations. A listing of all FA present at $>0.5 \%$ of the total FA in each product analysed is shown in Table 2. 
Table 2. A catalogue of fatty acids (FA) quantified, together with the composition (as percent of total FA) of all products. Abbreviations used for oil products are: Swisse Krill Oil (SW); Norkrill (Nor); Bio-organics (Bio-O); Blackmores Omega (B- $\Omega$ ); Bioceuticals (BCT); Blackmores Joint (B-Joint); Nature's Way Kidsmart (NWK); Blackmores Pregnancy (B-P); Nature's Own 1000 mg (NO-1000); Blackmore's $1000 \mathrm{mg}$ (B-1000); Cenovis $1000 \mathrm{mg}$ (C-1000). Capsules or subsamples from two separate batches of each product were pooled for each FA analysis, except for Blackmores Omega Liquid Fish Oil for which only a single batch number could be sourced. Other: denotes FA present at $<0.5 \%$ in all products.

\begin{tabular}{|c|c|c|c|c|c|c|c|c|c|c|c|}
\hline Product & SW & Nor & Bio-O & B- $\Omega$ & BCT & B-Joint & NWK & B-P & NO-1000 & B-1000 & C-1000 \\
\hline \multicolumn{12}{|l|}{ FA } \\
\hline $14: 0$ & 7.3 & 8 & 1.9 & 0.37 & 4.3 & 0.12 & 3.3 & 5.06 & 6.3 & 2.4 & 6.1 \\
\hline $15: 0$ & 0.33 & 0.33 & 0.15 & 0.02 & 0.3 & 0 & 0.64 & 0.46 & 0.58 & 0.2 & 0.44 \\
\hline $16: 4$ & 0.7 & 0.77 & 1.4 & 0.1 & 2.6 & 0.98 & 0.31 & 0.24 & 2.3 & 1.4 & 2.3 \\
\hline $16: 3$ & 0.22 & 0.23 & 1 & 0.05 & 2.2 & 0.53 & 0.27 & 0.2 & 1.6 & 0.9 & 1.6 \\
\hline $16: 1 \oplus 7 \mathrm{c}$ & 6.4 & 5.6 & 3.3 & 0.55 & 5.7 & 1.07 & 5.1 & 4.3 & 10 & 4.1 & 11 \\
\hline $16: 1 \oplus 5 c$ & 0.48 & 0.54 & 0.07 & 0 & 0.12 & 0.01 & 0.14 & 0.11 & 0.21 & 0.07 & 0.21 \\
\hline $16: 0$ & 19 & 23 & 5 & 3.2 & 11 & 0.18 & 19 & 20 & 17 & 5.6 & 15 \\
\hline $\operatorname{Br} 17: 1$ & 0.1 & 0.06 & 0.16 & 0.03 & 0.28 & 0.12 & 0.57 & 0.52 & 0.35 & 0.19 & 0.31 \\
\hline $17: 1 \oplus 8 c+a 17: 0$ & 0.27 & 0.25 & 0.18 & 0.1 & 0.3 & 0.06 & 0.7 & 0.6 & 0.41 & 0.18 & 0.41 \\
\hline $17: 0$ & 0.09 & 0.1 & 0.17 & 0.19 & 0.28 & 0.01 & 0.86 & 0.83 & 0.53 & 0.18 & 0.47 \\
\hline $18: 4 \oplus 3$ & 2.9 & 3.4 & 4.3 & 1.5 & 3.6 & 3.9 & 1.1 & 0.89 & 2.9 & 3.5 & 2.7 \\
\hline $18: 2 \oplus 6$ & 2.3 & 2 & 1.1 & 0.75 & 1.2 & 0.9 & 3.4 & 9.03 & 1.5 & 1.1 & 1.4 \\
\hline $18: 3 \oplus 3$ & 1 & 1.2 & 0.68 & 0.43 & 0.46 & 0.59 & 0.73 & 1.4 & 0.81 & 0.65 & 0.69 \\
\hline $18: 1 \oplus 9 c$ & 11 & 9.8 & 5.6 & 6.5 & 6.5 & 1.37 & 11 & 13 & 9 & 3.9 & 8.6 \\
\hline $18: 1 \oplus 7 \mathrm{c}$ & 8.2 & 7.2 & 2.3 & 2.6 & 2.6 & 0.94 & 2.4 & 2.6 & 4 & 2 & 4.2 \\
\hline 18:0 & 1.01 & 1.1 & 1.7 & 3.6 & 2.9 & 0.11 & 14 & 7.8 & 3.6 & 1.2 & 3.4 \\
\hline $20: 4 \oplus 6$ & 0.19 & 0 & 3.4 & 0.29 & 0.5 & 0.15 & 1.3 & 1.3 & 0.63 & 0.23 & 0.41 \\
\hline $20: 5 \oplus 3$ & 20 & 21 & 37 & 35 & 24 & 62 & 6.9 & 5.7 & 18 & 47 & 19 \\
\hline $20: 4 \oplus 3$ & 0.49 & 0.52 & 1.3 & 1.7 & 1.1 & 2 & 0.48 & 0.43 & 0.89 & 1.6 & 0.9 \\
\hline $20: 1 \oplus 9 c$ & 0.69 & 0.7 & 1 & 3.05 & 1.4 & 0.56 & 1.3 & 1 & 1.09 & 0.73 & 0.97 \\
\hline $20: 1 \oplus 7 \mathrm{c}$ & 0.38 & 0.4 & 0.26 & 0.72 & 0.5 & 0.07 & 0.17 & 0.15 & 0.45 & 0.2 & 0.47 \\
\hline
\end{tabular}


Table 2. Cont.

\begin{tabular}{cccccccccccc}
\hline Product & SW & Nor & Bio-O & B- $\Omega$ & BCT & B-Joint & NWK & B-P & NO-1000 & B-1000 & C-1000 \\
\hline FA & & & & & & & & & & & \\
\hline $21: 5 \oplus 3$ & 0.48 & 0.63 & 1.3 & 1.6 & 1.1 & 2.4 & 0.22 & 0.19 & 0.68 & 1.8 & 0.71 \\
$22: 5 \oplus 6$ & 0.01 & 0 & 0.25 & 0.46 & 0.17 & 0.29 & 0.71 & 1.1 & 0.27 & 0.27 & 0.22 \\
$22: 6 \omega 3$ & 12 & 9.8 & 20 & 25 & 18 & 16 & 20 & 18 & 11 & 14 & 12 \\
$22: 5 \omega 3$ & 0.46 & 0.57 & 2.7 & 4.8 & 3.4 & 4.4 & 1.3 & 1.2 & 2.3 & 3.7 & 2.6 \\
$22: 1 \omega 11 \mathrm{c}$ & 0 & 0 & 0.6 & 2.3 & 1.1 & 0.02 & 0.67 & 0.49 & 0.55 & 0.2 & 0.59 \\
$22: 1 \omega 9 \mathrm{c}$ & 0.48 & 0.79 & 0.15 & 0.49 & 0.27 & 0.05 & 0.17 & 0.14 & 0.2 & 0.1 & 0.19 \\
$24: 1 \omega 9 \mathrm{c}$ & 0.17 & 0.19 & 0.24 & 0.53 & 0.53 & 0 & 0.37 & 0.39 & 0.46 & 0.15 & 0.45 \\
Other & 3.09 & 2.39 & 2.71 & 4.16 & 3.61 & 1.59 & 3.45 & 3.39 & 2.8 & 1.87 & 3.19 \\
Total & 100 & 100 & 100 & 100 & 100 & 100 & 100 & 100 & 100 & 100 & 100 \\
\hline
\end{tabular}

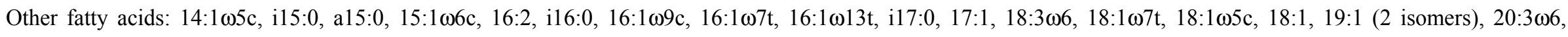

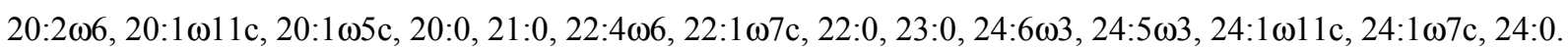


Table 3. Observed versus manufacturer labelled EPA and DHA values of selected fish and krill oil nutriceutical categories and products (labelled and values are rounded to two significant figures). Capsules or subsamples from two separate batches of each product were pooled for each FA analysis, except for Blackmores Omega Liquid Fish Oil for which only a single batch number could be sourced.

\begin{tabular}{|c|c|c|c|c|c|c|}
\hline Product & $\begin{array}{l}\text { Labelled EPA (mg) } \\
\text { Per Capsule/Serve }\end{array}$ & $\begin{array}{c}\text { Observed EPA (mg) } \\
\text { Per Capsule/Serve }\end{array}$ & $\begin{array}{l}\text { Labelled DHA (mg) } \\
\text { Per Capsule/Serve }\end{array}$ & $\begin{array}{c}\text { Observed DHA (mg) } \\
\text { Per Capsule/Serve }\end{array}$ & $\begin{array}{l}\text { EPA + DHA (mg) per Max } \\
\text { Recommended Daily Serve }\end{array}$ & $\begin{array}{c}\text { Cost (AUD) } \\
\text { Per (Labelled) 500 mg } \\
\text { DHA + EPA }\end{array}$ \\
\hline \multicolumn{7}{|c|}{ Krill Oil } \\
\hline Swisse (NKO) & 50 & 55 & 30 & 33 & 240 & 3.8 \\
\hline Norkrill (Aker Biomarine) & 60 & 86 & 28 & 40 & 180 & 4.0 \\
\hline \multicolumn{7}{|c|}{ Enriched Fish Oils } \\
\hline BioOrganics super liquid & 1600 & 1600 & 810 & 860 & 2400 & 0.21 \\
\hline Blackmores Omega Liquid & 1700 & 1500 & 1100 & 1100 & 2800 & 0.24 \\
\hline Bioceuticals omegasure Liquid & 1050 & 1300 & 750 & 790 & 1800 & 0.28 \\
\hline \multicolumn{7}{|c|}{ Formulations } \\
\hline Blackmores Omega Joint & 550 & 590 & 120 & 150 & 2700 & 0.40 \\
\hline Nature's way kidsmart & 28 & 33 & 130 & 95 & 320 & 0.90 \\
\hline Blackmores Pregnancy & 25 & 27 & 130 & 86 & 300 & 2.7 \\
\hline \multicolumn{7}{|c|}{ 18:12 Standard Grade } \\
\hline Nature's Own Odourless 1000 & 180 & 180 & 120 & 110 & 2700 & 0.15 \\
\hline Blackmores Odourless 1000 & 180 & 180 & 120 & 110 & 3600 & 0.10 \\
\hline Cenovis 1000 & 175 & 180 & 70 & 120 & 250 & 0.25 \\
\hline
\end{tabular}




\subsection{Persistent Organic Pollutants}

None of the categories or products analysed in the current study, at their highest recommended dosage, came close to fulfilling tolerable daily intake (TDI) levels for any single analyte (Table 4). Despite the fact that environmental exposure to POPs does not occur to a single residue at a time, but rather to complex and interacting mixtures, this finding is reassuring. As a means of qualitatively comparing and contrasting the eleven products analysed in this study, and providing an overview of chemical summaries obtained, we devised a simple scoring system (Table 5). The five products with the greatest contaminant burden for five key compound groups, plus TEQ values, were ranked from 1-5 with the sample containing the highest concentrations receiving a score of 5. Bioceuticals Omegasure liquid fish oil and Blackmores $1000 \mathrm{mg}$ both carried a cumulative score of 16 reflecting their placement among the top five products for five and four compound/index groups respectively. Blackmores Pregnancy and Breastfeeding Gold formula and Nature's Own $1000 \mathrm{mg}$ each received a score of 12. Blackmore's Pregnancy and Breastfeeding Gold formula incorporates tuna oil, sourced from northern hemisphere oceans, thereby likely contributing to the higher contaminant burdens found in this formulation, despite its lower oil content. Blackmore's Joint formula was the only product which did not feature among the top five products for any analyte or index group. 
Table 4. Chemical burdens per maximum recommended daily dose (lipid); where relevant, corresponding TEQ (2005) and percent (\%) of Tolerable Daily Intake (TDI). Values are presented to two significant figures. Blank squares indicate that values fell below the method level of detection (LOD), which are given as an average concentration for all 11 products (pg/g lipid), whilst grey squares indicate that corresponding congeners were not analysed for that product. Abbreviations used for oil products are: Swisse Krill Oil (SW); Norkrill (Nor); Bio-organics (Bio-O); Blackmores Omega (B- $\Omega$ ); Bioceuticals (BCT); Blackmores Joint (B-Joint); Nature's Way Kidsmart (NWK); Blackmores Pregnancy (B-P); Nature's Own 1000 mg (NO-1000); Blackmore's 1000mg (B-1000); Cenovis 1000 mg (C-1000). Capsules or subsamples from two separate batches of each product were pooled for each POP analysis, except for Blackmores Omega Liquid Fish Oil for which only a single batch number could be sourced.

\begin{tabular}{|c|c|c|c|c|c|c|c|c|c|c|c|c|}
\hline $\begin{array}{c}\text { Compound } \\
\text { (LOD, pg/g Lipid) }\end{array}$ & $\begin{array}{c}\text { TDI }{ }^{a}(p g) / D a y ~ P e r \\
60 \mathrm{~kg} \text { Adult } \\
\end{array}$ & $\begin{array}{c}\text { SW } \\
(\mathrm{pg} / \mathbf{1} \mathrm{g})\end{array}$ & $\begin{array}{c}\text { Nor } \\
(\mathrm{pg} / 1 \mathrm{~g}) \\
\end{array}$ & $\begin{array}{c}\text { Bio-O } \\
(\mathrm{pg} / 4.75 \mathrm{~g}) \\
\end{array}$ & $\begin{array}{c}\mathrm{B}-\Omega \\
(\mathrm{pg} / 4.75 \mathrm{~g}) \\
\end{array}$ & $\begin{array}{c}\text { BCT } \\
(\mathrm{pg} / 4.75 \mathrm{~g}) \\
\end{array}$ & $\begin{array}{l}\text { B-Joint } \\
\text { (pg/4 g) }\end{array}$ & $\begin{array}{r}\text { NWK } \\
(\mathrm{pg} / \mathbf{1 g})\end{array}$ & $\begin{array}{c}\text { B-P } \\
(\mathrm{pg} / \mathbf{0 . 8 6} \mathrm{g}) \\
\end{array}$ & $\begin{array}{r}\text { NO-1000 } \\
(\mathrm{pg} / 9 \mathrm{~g}) \\
\end{array}$ & $\begin{array}{r}\text { B-1000 } \\
(\mathrm{pg} / 12 \mathrm{~g})\end{array}$ & $\begin{array}{l}\mathrm{C}-1000 \\
(\mathrm{pg} / \mathrm{g} \mathrm{g}) \\
\end{array}$ \\
\hline \multicolumn{13}{|l|}{$\mathrm{HCH}$} \\
\hline $\mathrm{a}-\mathrm{HCH}$ (27) & & & & 180 & & & & & 260 & & & \\
\hline b-HCH (32) & & 72 & & 370 & & & & & 270 & & 690 & 260 \\
\hline g-HCH (29) & & 65 & 33 & 170 & & & & & 1700 & & & \\
\hline$\sum \mathrm{HCH}$ & $18,000,000^{\mathrm{c}}$ & $(0.00076)$ & $(0.00018)$ & $(0.004)$ & & & & & $(0.012)$ & & $(0.0038)$ & $(0.0014)$ \\
\hline \multicolumn{13}{|l|}{$D D T$} \\
\hline o,p'-DDE (46) & & & & & 480 & 810.0 & & 1800.0 & & 49,000 & & \\
\hline p,p'-DDE (59) & & & & & 1000 & 16,000 & 1200 & 5000 & 15,000 & 120,000 & 35,000 & \\
\hline o,p'-DDD (37) & & & & & & 840 & & 890 & 7100 & 1300 & & \\
\hline p,p'-DDD (40) & & 180 & & 10,000 & & 6700 & & 4900 & 31,000 & 20,000 & 25,000 & 11,000 \\
\hline o,p'-DDT (43) & & 260 & & 1300 & & 1100 & & 270 & 26,000 & 2000 & 3600 & 1000 \\
\hline p,p'-DDT (69) & & & & & 1400 & 4400 & & 5100 & 80,000 & 140,000 & 9000 & 2100 \\
\hline$\sum \mathrm{DDT}$ & $30,000,000^{\mathrm{c}}$ & $(0.0015)$ & & $(0.038)$ & $(0.0095)$ & $(0.1)$ & $(0.004)$ & $(0.06)$ & $(0.53)$ & (1.1) & $(0.24)$ & $(0.047)$ \\
\hline
\end{tabular}


Table 4. Cont.

\begin{tabular}{|c|c|c|c|c|c|c|c|c|c|c|c|c|}
\hline Compound & $\begin{array}{c}\text { TDI }^{\mathrm{a}}(\mathrm{pg}) / \mathrm{Day} \\
\text { Per } 60 \mathrm{~kg} \text { Adult }\end{array}$ & $\begin{array}{c}\text { SW } \\
(\mathrm{pg} / \mathbf{1} \mathrm{g})\end{array}$ & $\begin{array}{c}\text { Nor } \\
(\mathrm{pg} / \mathbf{1} \mathrm{g})\end{array}$ & $\begin{array}{c}\text { Bio-O } \\
\text { (pg/4.75 g) } \\
\end{array}$ & $\begin{array}{c}\mathrm{B}-\Omega \\
(\mathrm{pg} / 4.75 \mathrm{~g})\end{array}$ & $\begin{array}{c}\text { BCT } \\
(\mathrm{pg} / 4.75 \mathrm{~g}) \\
\end{array}$ & $\begin{array}{l}\text { B-Joint } \\
\text { (pg/4 g) }\end{array}$ & $\begin{array}{c}\text { NWK } \\
(\mathrm{pg} / \mathbf{1} \mathrm{g})\end{array}$ & $\begin{array}{c}\text { B-P } \\
\text { (pg/1.72 g) }\end{array}$ & $\begin{array}{c}\text { NO-1000 } \\
(\mathrm{pg} / \mathbf{9} \mathrm{g})\end{array}$ & $\begin{array}{c}\mathrm{B}-1000 \\
(\mathrm{pg} / 12 \mathrm{~g})\end{array}$ & $\begin{array}{l}\mathrm{C}-1000 \\
(\mathrm{pg} / \mathbf{9} \mathrm{g})\end{array}$ \\
\hline \multicolumn{13}{|l|}{ Chlordanes } \\
\hline trans-Chlordane (60) & & & & & & 4000 & & & & & & \\
\hline cis-Chlordane (160) & & & & & & 2300 & & & & & & \\
\hline oxy-Chlordane (1500) & & & & & 30,000 & & & & & & & \\
\hline cis-Nonachlor (28) & & & & & & 1700 & & 100 & & & & \\
\hline$\sum$ Chlordane & $30,000,000^{\mathrm{c}}$ & & & & $(0.1)$ & $(0.027)$ & & $(0.000028)$ & & & & \\
\hline Endosulfan-I (34) & $360,000,000^{\mathrm{c}}$ & & & $390.0(0.00011)$ & & & & & & & & \\
\hline \multicolumn{13}{|l|}{ Toxaphene } \\
\hline Tox-26 (61) & & & & & & 2400 & & & & & & \\
\hline Tox-40 + Tox-41 (48) & & & & & & 2300 & & 260 & 770 & & & 3500 \\
\hline Tox-44 (160) & & & & & & 7800 & & 1100 & & & & 13,000 \\
\hline Tox-50 (23) & & & & & & 6200 & & 330 & 1100 & & & 5200 \\
\hline$\sum$ Toxaphene & $12,000,000^{\mathrm{d}}$ & & & & & $(0.16)$ & & $(0.014)$ & $(0.016)$ & & & $(0.18)$ \\
\hline \multicolumn{13}{|l|}{ Chlorobenzenes } \\
\hline $\operatorname{PeCB}(3.1)$ & $60,000,000^{\mathrm{b}}$ & $930(0.0016)$ & $340(0.00057)$ & $59(0.0001)$ & & $300(0.0005)$ & $180(0.0003)$ & $91(0.00015)$ & $190(0.00032)$ & & & $160(0.00027)$ \\
\hline $\mathrm{HCB}(2.8)$ & $9,600,000^{\mathrm{e}}$ & $9900(0.1)$ & $4400(0.046)$ & $68(0.00071)$ & & $780(0.0081)$ & $160(0.0017)$ & $27(0.00028)$ & $500(0.0052)$ & & & $140(0.0015)$ \\
\hline
\end{tabular}


Table 4. Cont.

\begin{tabular}{|c|c|c|c|c|c|c|c|c|c|c|c|c|}
\hline Compound & $\begin{array}{c}\text { TDI }^{\mathrm{a}} \text { (pg)/Day } \\
\text { Per } 60 \mathrm{~kg} \text { Adult }\end{array}$ & $\begin{array}{c}\mathrm{SW} \\
(\mathrm{pg} / \mathbf{1} \mathrm{g})\end{array}$ & $\begin{array}{c}\text { Nor } \\
\text { (pg/1 g) }\end{array}$ & $\begin{array}{c}\text { Bio-O } \\
\text { (pg/4.75 g) }\end{array}$ & $\begin{array}{c}\text { B- } \Omega \\
\text { (pg/4.75 g) }\end{array}$ & $\begin{array}{c}\text { BCT } \\
(\mathrm{pg} / 4.75 \mathrm{~g})\end{array}$ & $\begin{array}{l}\text { B-Joint } \\
\text { (pg/4 g) }\end{array}$ & $\begin{array}{c}\text { NWK } \\
(\mathrm{pg} / \mathbf{1} \mathrm{g})\end{array}$ & $\begin{array}{c}\text { B-P } \\
(\mathrm{pg} / \mathbf{0 . 8 6} \mathrm{g})\end{array}$ & $\begin{array}{c}\text { NO-1000 } \\
(\mathrm{pg} / \mathbf{9} \mathrm{g})\end{array}$ & $\begin{array}{c}\mathrm{B}-1000 \\
(\mathrm{pg} / 12 \mathrm{~g})\end{array}$ & $\begin{array}{l}\mathrm{C}-1000 \\
(\mathrm{pg} / 9 \mathrm{~g})\end{array}$ \\
\hline$P C B$ & & Conc. (TEQ) & Conc. (TEQ) & Conc. (TEQ) & Conc. (TEQ) & Conc. (TEQ) & Conc. (TEQ) & Conc. (TEQ) & Conc. (TEQ) & Conc. (TEQ) & Conc. (TEQ) & Conc. (TEQ) \\
\hline $18(14)$ & & 38 & 14 & & & 150 & 86 & & 52 & & 140 & \\
\hline $28(10)$ & & 48 & 20 & & 72 & 370 & 83 & & 130 & 590 & & \\
\hline $31(10)$ & & 45 & 21 & & 50 & 230 & 91 & & 68 & & 190 & \\
\hline $33(10)$ & & & 13 & & & 64 & 56 & & & & 150 & \\
\hline $47(4.8)$ & & 48 & 75 & & 210 & 420 & 46 & & 240 & 260 & 310 & \\
\hline $52(5.4)$ & & 130 & & & & 130 & 96 & 13 & 360 & & & 140 \\
\hline $66(4.6)$ & & 57 & 14 & & & 850 & & & 600 & 790 & 600 & 260 \\
\hline $74(4.0)$ & & 30 & & & & 550 & & & 210 & 280 & 250 & 100 \\
\hline $77(0.11)$ & & & & $10(0.0011)$ & & $18(0.0018)$ & & $0.59(0.000059)$ & $9.4(0.00094)$ & $54(0.0054)$ & $110(0.011)$ & \\
\hline $81(0.10)$ & & $0.51(0.00015)$ & & & $0.48(0.00014)$ & $0.38(0.00011)$ & & & & $1.1(0.00033)$ & & \\
\hline $99(5.7)$ & & 64 & 12 & 93 & & 2300 & & 38 & 820 & 920 & 130 & 510 \\
\hline $101(6.3)$ & & 170 & 42 & 190 & & 3700 & 62 & 69 & 900 & 1900 & 2800 & 1000 \\
\hline $105(7.6)$ & & $34(0.0010)$ & & $130(0.0039)$ & & $1200(0.036)$ & & $19(0.00057)$ & $210(0.0063)$ & $1100(0.033)$ & $1600(0.048)$ & $720(0.022)$ \\
\hline $114(5.8)$ & & & & & & $120(0.0036)$ & & & & & $130(0.065)$ & \\
\hline
\end{tabular}


Table 4. Cont.

\begin{tabular}{|c|c|c|c|c|c|c|c|c|c|c|c|c|}
\hline Compound & $\begin{array}{c}\text { TDI }^{\text {a }}(\mathrm{pg}) / \mathrm{Day} \\
\text { Per } 60 \mathrm{~kg} \text { Adult }\end{array}$ & $\begin{array}{c}\mathrm{SW} \\
(\mathrm{pg} / \mathbf{1} \mathrm{g}) \\
\end{array}$ & $\begin{array}{c}\text { Nor } \\
\text { (pg/1 g) } \\
\end{array}$ & $\begin{array}{c}\text { Bio-O } \\
\text { (pg/4.75 g) } \\
\end{array}$ & $\begin{array}{c}\mathrm{B}-\Omega \\
(\mathrm{pg} / 4.75 \mathrm{~g})\end{array}$ & $\begin{array}{c}\text { BCT } \\
(\mathrm{pg} / 4.75 \mathrm{~g}) \\
\end{array}$ & $\begin{array}{l}\text { B-Joint } \\
\text { (pg/4 g) }\end{array}$ & $\begin{array}{c}\text { NWK } \\
(\mathrm{pg} / \mathbf{1} \mathrm{g})\end{array}$ & $\begin{array}{c}\text { B-P } \\
(\mathrm{pg} / 0.86 \mathrm{~g}) \\
\end{array}$ & $\begin{array}{c}\text { NO-1000 } \\
(\mathrm{pg} / \mathbf{9} \mathrm{g})\end{array}$ & $\begin{array}{c}\text { B-1000 } \\
\text { (pg/12 g) } \\
\end{array}$ & $\begin{array}{l}\mathrm{C}-1000 \\
(\mathrm{pg} / 9 \mathrm{~g}) \\
\end{array}$ \\
\hline$P C B$ & & Conc. (TEQ) & Conc. (TEQ) & Conc.(TEQ) & Conc.(TEQ) & Conc. (TEQ) & Conc. (TEQ) & Conc. (TEQ) & Conc. (TEQ) & Conc. (TEQ) & Conc. (TEQ) & Conc. (TEQ) \\
\hline $118(5.7)$ & & $75(0.0023)$ & $0.017(0.000001)$ & $340(0.01)$ & & $3500(0.11)$ & & $0.067(0.000002)$ & $690(0.021)$ & $2600(0.078)$ & $4000(0.12)$ & $1600(0.048)$ \\
\hline $122(6.3)$ & & & & & & & & & & & & 140 \\
\hline $123(6.3)$ & & & & & & $55(0.0017)$ & & $13(0.00039)$ & $110(0.0033)$ & & & $230(0.0069)$ \\
\hline $126(0.43)$ & & $1.8(0.18)$ & $0.94(0.094)$ & $5.5(0.55)$ & $1.8(0.18)$ & $4.6(0.46)$ & & & & $24(2.4)$ & $50(5.0)$ & \\
\hline $128(8.1)$ & & 21 & & 120 & & 1100 & & 69 & 310 & 1200 & 1500 & 690 \\
\hline $138(6.9)$ & & 110 & 15 & 790 & 60 & 7100 & 53 & 380 & 1800 & 6700 & 10,000 & 4300 \\
\hline $141(4.8)$ & & 18 & & 110 & & 850 & & 50 & 220 & 1000 & 1400 & 640 \\
\hline $149(4.3)$ & & 100 & 19 & 320 & & 2700 & 52 & 120 & 75 & 3100 & 4400 & 1700 \\
\hline $153(4.1)$ & & 140 & 25 & 1200 & 76 & 9200 & 75 & 50 & 2600 & 9900 & 14,000 & 5500 \\
\hline $156(6.9)$ & & & & & & $450(0.014)$ & & $30(0.0009)$ & $150(0.0045)$ & $530(0.016)$ & $810(0.024)$ & $460(0.014)$ \\
\hline $157(5.7)$ & & & & & & $100(0.003)$ & & & & $110(0.0033)$ & $200(0.006)$ & $91(0.0027)$ \\
\hline 167 (5.9) & & & & $51(0.00051)$ & & $260(0.0026)$ & & $19(0.00019)$ & $107(0.053)$ & $370(0.037)$ & $550(0.055)$ & $250(0.025)$ \\
\hline $169(0.28)$ & & $1.4(0.042)$ & $0.86(0.026)$ & $2.1(0.063)$ & $0.83(0.025)$ & & & & & $3.6(0.11)$ & $8.8(0.26)$ & \\
\hline $170(7.7)$ & & 18 & & 320 & 71 & 1400 & & 150 & & 2100 & 3500 & 1700 \\
\hline $180(7.3)$ & & & & 770 & 130 & 4000 & 62 & 590 & 2300 & 6600 & 9800 & 4700 \\
\hline $183(5.7)$ & & & & 100 & 47 & 630 & 40 & 56 & 190 & 880 & 1100 & 560 \\
\hline $187(6.0)$ & & 43 & & 320 & & 1800 & & 190 & 440 & 2600 & 3700 & 1600 \\
\hline $189(7.7)$ & & & & & & & & & & & $250(0.0075)$ & \\
\hline $194(5.3)$ & & & & 110 & 59 & 57 & & 83 & 180 & 910 & 1200 & 640 \\
\hline $206(6.8)$ & & & & & & & & 36 & & 200 & 290 & 160 \\
\hline 209 (2.4) & & & & & & 120 & & 23 & 106 & & & 92 \\
\hline $\begin{array}{l}\sum \mathrm{PCB} \\
(\% \mathrm{TDI}) \\
\end{array}$ & $7,800,000^{\mathrm{b}}$ & $1200(0.015)$ & $270(0.0035)$ & $5000(0.064)$ & $1000(0.013)$ & $4600(0.59)$ & $800(0.01)$ & $2500(0.032)$ & $14,000(0.17)$ & $45,000(0.58)$ & $65,000(0.83)$ & $29,000(0.37)$ \\
\hline
\end{tabular}


Table 4. Cont.

\begin{tabular}{|c|c|c|c|c|c|c|c|c|c|c|c|c|}
\hline Compound & $\begin{array}{l}\text { TDI a }(\mathrm{pg}) / \text { Day } \\
\text { per } 60 \mathrm{~kg} \text { Adult }\end{array}$ & $\begin{array}{c}\mathrm{SW} \\
(\mathrm{pg} / \mathbf{1} \mathrm{g}) \\
\end{array}$ & $\begin{array}{c}\text { Nor } \\
(\mathrm{pg} / \mathbf{1} \mathrm{g}) \\
\end{array}$ & $\begin{array}{c}\text { Bio-O } \\
\text { (pg/4.75 g) }\end{array}$ & $\begin{array}{c}\mathrm{B}-\Omega \\
(\mathrm{pg} / 4.75 \mathrm{~g}) \\
\end{array}$ & $\begin{array}{c}\text { BCT } \\
(\mathrm{pg} / 4.75 \mathrm{~g}) \\
\end{array}$ & $\begin{array}{l}\text { B-Joint } \\
\text { (pg/4 g) }\end{array}$ & $\begin{array}{l}\text { NWK } \\
(\mathrm{pg} / \mathbf{1} \mathrm{g})\end{array}$ & $\begin{array}{c}\text { B-P } \\
\text { (pg/0.86 g) } \\
\end{array}$ & $\begin{array}{c}\text { NO-1000 } \\
(\mathrm{pg} / \mathbf{9} \mathrm{g})\end{array}$ & $\begin{array}{c}\mathrm{B}-1000 \\
(\mathrm{pg} / 12 \mathrm{~g})\end{array}$ & $\begin{array}{l}\mathrm{C}-1000 \\
(\mathrm{pg} / 9 \mathrm{~g}) \\
\end{array}$ \\
\hline Dioxin/Furans & & Conc. (TEQ) & Conc. (TEQ) & Conc. (TEQ) & Conc. (TEQ) & Conc. (TEQ) & Conc. (TEQ) & Conc. (TEQ) & Conc. (TEQ) & Conc. (TEQ) & Conc. (TEQ) & Conc. (TEQ) \\
\hline OCDD $(0.41)$ & & & & $30(0.009)$ & $7.4(0.0022)$ & $73(0.022)$ & & & & & & \\
\hline 2378-TCDF (0.49) & & $0.54(0.054)$ & $0.15(0.015)$ & & & & & & & $0.72(0.072)$ & & \\
\hline 23478-PeCDF (2.3) & & & $0.19(0.095)$ & & & & & & & & & \\
\hline 123478/123479-HxCDF (0.19) & & & $0.049(0.0049)$ & & & & & & & & & \\
\hline$\sum \mathrm{TEQ}$ & 120 TEQ/Day & $0.23 \%$ & $0.18 \%$ & $0.53 \%$ & $0.17 \%$ & $0.55 \%$ & & $0.0018 \%$ & $0.071 \%$ & $1.5 \%$ & $4.7 \%$ & $0.10 \%$ \\
\hline
\end{tabular}

a Values are based on current scientific information and may change; ${ }^{\mathrm{b}}$ Health Canada, 2007 [29]; ${ }^{\mathrm{c}}$ US EPA [30]; ${ }^{\mathrm{d}}$ Man Chan et al. (2000) [31]; ${ }^{\mathrm{e}}$ IPCS (1997) [32]. 
Table 5. Ranking (1-5) of products according to analyte or TEQ category where a score of 5 denotes the highest concentration/index value.

\begin{tabular}{cccccccc}
\hline & $\sum$ HCH & $\sum$ DDT & $\sum$ Chl & HCB & $\sum$ PCB & TEQ & Score \\
\hline SW & 1 & & & 5 & & 1 & 7 \\
Nor & & & & 4 & & & 4 \\
Bio-O & 4 & & & & & 2 & 6 \\
B- $\Omega$ & & & 5 & & & & 5 \\
BCT & & 2 & 4 & 3 & 4 & 3 & 16 \\
B-Joint & & & & 1 & & & 1 \\
NWK & & 1 & 3 & & & & 4 \\
B-P & 5 & 4 & & 2 & 1 & & 12 \\
NO-1000 & & 5 & & & 3 & 4 & 12 \\
B-1000 & 3 & 3 & & & 5 & 5 & 16 \\
C-1000 & 2 & & & & 2 & & 4 \\
\hline
\end{tabular}

Hexachlorocyclohexane $(\mathrm{HCH})$ congeners did not feature prominently in any product profiles, possibly reflecting the slightly lower lipophilicity of this compound group. The DDT group included the highest concentration of any single compound, with $13 \mathrm{ng} / \mathrm{g}$ lipid p,p'-DDE detected in Nature's Own $1000 \mathrm{mg}$ standard fish oil product, equalling a maximum daily dose $120 \mathrm{ng}$ of p,p'-DDE. Notably, only one krill oil formulation (Swisse) showed detectable levels of $\sum$ DDT. p,p'-DDE has repeatedly been found to be one of the dominant congeners accumulating in Antarctic krill and their predators [26,33-38]. Previously, the authors have reported a comprehensive overview of baseline contamination in Antarctic krill [26], with HCB and p,p'-DDE dominating the described profiles. Further, team studies on dependent populations of humpback whales (Megaptera novaeangliae), found that the profiles of these predators closely mirrored the profiles of their principal prey, Antarctic krill. In the case of the krill oil products analysed in the current study, however, only trace (440 pg/g lipid or daily dose) levels were quantified in the Swisse krill oil brand which may indicate purification through the manufacturing process.

Detectable levels of chlordanes were observed in only three products, namely Bio-Organics Super Liquid fish Oil (30 ng per maximum daily dose), Bioceuticals Omegasure fish oil (4.6 ng per maximum daily dose) and Nature's Way Kidsmart (0.1 ng per daily dose). Similarly, endosulfan-I was only detected at trace levels (390 pg/g lipid) in BioOrganics Super Liquid fish oil.

Toxaphene structures were not quantified in five of the eleven products due to loss of the analytes during clean-up. However, notable quantities were detected in Cenovis $1000 \mathrm{mg}$ (19 ng/daily dose; 0.15\% TDI) and Bioceuticals Omegasure fish oil (16 ng/daily dose; 0.14\% TDI). Only trace levels of toxaphene were quantified in Nature's Way Kidsmart and Blackmores Pregnancy and Breastfeeding formulation. These congeners were undetectable in Blackmores Joint formula and BioOrganics Super Liquid fish oil.

Chlorobenzenes (penta- and hexa-) were quantified in eight of eleven products at levels ranging from 27-9900 pg/maximum daily dose. Antarctic krill products carried the highest levels of chlorobenzene contamination for both penta- and hexa- congeners. The higher levels of particularly $\mathrm{HCB}$, in Antarctic krill oil is not surprising as this has repeatedly been shown to be the compound dominating POP profiles of the Antarctic sea-ice ecosystem food-web [26,33,34]. The finding that 
levels were greater than any other product categories, sourced from other global regions, however, was unexpected as HCB has been postulated to be approaching global equilibrium [39]. This finding does not support equilibrium conditions and may be reflective of cold trapping or remobilisation processes of the compound in Polar Regions, combined with steady removal from temperate or tropical source regions.

Polychlorinated biphenyls (PCBs) were detected in all products at cumulative levels ranging from $0.01 \%$ TDI (Blackmores Joint formula) to $0.94 \%$ TDI (Blackmores $1000 \mathrm{mg}$ ). Krill oil products were at the lower end of the spectrum $(0.034 \%$ and $0.015 \%$ TDI for Swisse and Norkrill krill oil respectively), as is expected, given the manufacturing applications of these compounds and the lower historical usage in the southern hemisphere.

Dioxins and furans encompass a class of compounds which are not intentionally produced, but originate primarily through the manufacture of other chlorinated chemicals or combustion processes. Whilst the highest detected levels of any single dioxin or furan congener was $73.0 \mathrm{pg} / \mathrm{g}$ lipid of octachlorodibenzodioxin (OCDD) found in Bioceuticals Omegasure fish oil, only the krill oil products contained multiple detectable congeners. This is surprising given the low vapour pressure of dioxins and furans which predict long range atmospheric transport in association with particles. This in turn lowers their potential for effective transport to the Antarctic. Toxicity equivalencies (TEQ) are available for dioxins, furans and a sub-set of planar PCBs, and are calculated based upon their common mode of action. The single highest TEQ for any product analysed was obtained for Blackmores $1000 \mathrm{mg}$ standard fish oil product which yielded a TEQ of 5.6 TEQ or $4.7 \%$ of the 120 TEQ TDI. Swisse Krill oil, however, also featured among the top five highest ranking TEQ products. Dioxins, furans and planar PCBs are among the POP compounds most effeciently removed by common fish oil cleaning processes [40]. This finding therefore raises two possibilities. Either some of the fish oil products analysed are subject to one or more chemical purification steps during manufacture, reducing their original TEQ values to the ones observed here, with krill oil apparently not being subject to the same procedures. Alternatively processing and handling itself may have introduced contaminants to the krill oil product that were not present in the raw oil. The dioxin/furan profiles of krill oil here do not match the profiles of whole Antarctic krill previously analysed [25], providing support for the latter.

\section{Conclusions}

This study compared a range of readily available fish and krill oil dietary supplements for both their favourable long-chain omega-3 composition and content, as well as their persistent organic pollutant profiles. All products and categories adhered closely to manufacturer specifications and none exceeded chemical guideline thresholds. When krill oil was compared across categories to other fish oil products and formulations, it was the most expensive oil per $500 \mathrm{mg}$ DHA + EPA and adhered to manufacturer EPA and DHA specifications. The two krill oil products were ranked as intermediate in terms of their levels of POP contaminants when compared overall to the remaining omega-3 nutriceutical products selected for this study, with distinct chemical profiles reflecting their geographical region of origin. This study is the first to provide quantitative evaluation of toxicological profiles of Antarctic krill products, an emerging nutriceutical category. It hereby balances consumer information with regard to marketing of krill oil on the basis of product chemical purity. Ongoing monitoring of the pollutant 
content of fish and krill oil products will become increasingly important as food authorities seek regulatory overview of this rapidly expanding industry.

\section{Acknowledgments}

This study was in part funded by ARC Discovery Grant DP666891. The authors thank David McLagan and NILU laboratory staff for undertaking chemical analyses and Seanan Wild for undertaking lipid analyses. Danny Holdsworth managed the CSIRO GC and GC-MS facility. We also thank the two anonymous reviewers for their helpful comments on the manuscript.

\section{Author Contributions}

Susan Bengton Nash led and managed the study; Martin Schlabach oversaw chemical analyses at NILU whilst Peter Nichols oversaw lipid and fatty acid analyses at CSIRO. All authors contributed to the production of the manuscript.

\section{Conflicts of Interest}

The authors declare no conflict of interest.

\section{References}

1. Psota, T.L.; Gebauer, S.K.; Kris-Etherton, P. Dietary omega-3 fatty acid intake and cardiovascular risk. Am. J. Cardiol. 2006, 98, 3i-18i.

2. Maclean, C.H.; Newberry, S.J.; Mojica, W.A.; Khanna, P.; Issa, A.M.; Suttorp, M.J.; Lim, Y.; Traina, S.B.; Hilton, L.; Garland, R.; Morton, S.C. Effects of omega-3 fatty acids on cancer risk. J. Am. Med. Assoc. 2010, 295, 403-415.

3. Nichols, P.D. Seafood: Best sources of long-chain omega-3 oils and safe consumption. Agrofood 2008, 19, 20-22.

4. McCann, J.; Ames, B.N. Is docosahexaenoic acid, an n-3 long-chain polyunsaturated fatty acid, required for development of normal brain function? An overview of evidence from cognitive and behavioural tests in humans and animals. Am. J. Clin. Nutr. 2010, 82, 281-295.

5. Garg, M.L.; Wood, L.G.; Singh, H.; Moughan, P.J. Means of delivering reccommended levels of long chain n-3 polyunsaturated fatty acids in human diets. J. Food Sci. 2006, 71, R66-R71.

6. Deutsch, L. Evaluation of the effect of Neptune Krill Oil on chronic inflammation and arthritic symptoms. J. Am. Coll. Nutr. 2007, 26, 39-48.

7. Proudman, S.; Cleland, L.G.; James, M. Dietary omega-3 fats for treatment of inflammatory joint disease: Efficacy and utility. Rheum. Dis. Clin. North Am. 2008, 34, 469-479.

8. Peet, M.; Stokes, C. Omega-3 fatty acids in the treatment of psychiatric disorders. Drugs 2005, 65, 1051-1059.

9. Buhr, G.; Bales, C. Nutritional supplements for older adults: Review and reccommendations_-Part I. J. Nutr. Elder. 2009, 28, 5-29.

10. Meyer, B.; Mann, N.; Lewis, J.; Milligan, G.; Sinclair, A.; Howe, P. Dietary intake and food sources of omega-6 and omega-3 polyunsaturated fatty acids. Lipids 2003, 38, 392-397. 
11. Holub, B.J. Potential Benefits of Functional Food and Nutraceuticals to Reduce the Risk and Cost of Disease in Canada; Agriculture and Agri-food Canada: Ottawa, ON, Canada, 2002.

12. Grant, W.B.; Cross, H.S.; Garland, C.F.; Gorham, E.D.; Moan, J.; Peterlik, M.; Porojnicu, A.C.; Reichrath, J.; Zittermann, A. Estimated benefit of increased vitamin D status in reducing the economic burden of disease in western Europe. Prog. Biophys. Mol. Biol. 2009, 99, 104-113.

13. Nichols, P.D. Fish oil sources. In Long-Chain Omega-3 Specialty Oils; Breivik, H., Ed.; The Oily Press, PJ Barnes \& Associates: Bridgewater, UK, 2007; pp. 23-42.

14. Cansell, M.; Nacka, F.; Combe, N. Marine lipid-based liposomes increase in vivo FA bioavailability. Lipids 2003, 38, 551-559.

15. Bunea, R.; el Farrah, K.; Deutch, L. Evaluation of the effects of "Neptune" krill oil on the clinical course of hyperlipidemia. Altern. Med. Rev. 2004, 9, 420-428.

16. Atkinson, A.; Siegel, V.; Pakhomov, E.; Rothery, P. Long-term decline in krill stock and increase in salps within the Southern Ocean. Nature 2004, 432, 100-103.

17. Loeb, V.; Siegel, V.; Holm-Hansen, O.; Hewitt, R.P.; Fraser, W.; Trivelpiece, W.; Trivelpiece, S. Effects of sea-ice extent and krill or salp dominance on the Antarctic food web. Nature 1997, 387, 897-900.

18. Food and Agriculture Organization of the United Nations, World Health Organization. Report of the Second Session of the Codex Committee on Contaminants in Food. Available online: http://www.cclac.org/documentos/CCCF/2008/alinorm/al31_41e.pdf (accessed on 4 May 2014).

19. United Nations Environment Program (UNEP). Stockholm Convention on Persistent Organic Pollutants: Ammendments to Annexes A, B \& C; UNEP: Stockholm, Sweden, 2009.

20. Nicol, S. Krill, currents, and sea ice: Euphausia superba and its changing environment. BioScience 2006, 56, 111-120.

21. Wania, F.; Mackay, D. Global fractionation and cold condensation of low volatility organochlorine compounds in polar regions. Ambio 1993, 22, 10-18.

22. Alexander, J.; Froyland, L.; Hemre, G.; Jacobsen, B.; Lund, E.; Meltzer, H.; Skare, J. Et Helhetssyn pAa Fisk og Annen Sjomat i Norsk Kosthold (A Holistic View of Seafood in the Norwegian Diet); Norwegian Scientific Committee for Food Safety: Oslo, Norway, 2006.

23. Nielsen, E.; Larsen, J.C.; Ladefoged, O. Risk Assessment of Contaminant Intake from Traditional Greenland Food Items; Danish Veterinary and Food Administration: Glostrup, Denmark, 2006; p. 178.

24. Food Standards Authority Ireland (FSAI). Investigation on PCDD/PCDFs and Several PCBs in Fish Liver Oil Capsules; FSAI, Dublin, Ireland, 2002.

25. Halliday, J. Dioxins Prompt Second UK Fish Oil Withdrawal, 2006. Available online: http://www.nutraingredients.com/Regulation/Dioxins-prompt-second-UK-fish-oil-withdrawal (accessed on 4 May 2014).

26. Bengtson Nash, S.M.; Poulsen, A.H.; Kawaguchi, S.; Vetter, W.; Schlabach, M. Persistent organohalogen contaminant burdens in Antarctic Krill (Euphausia superba) from the eastern Antarctic sector: A Baseline Study. Sci. Total Environ. 2008, 407, 304-314.

27. Alhazzaa, R.; Bridle, A.R.; Nichols, P.D. Replacing dietary fish oil with Echium oil enriched barramundi with $\mathrm{C}_{18}$ PUFA rather than long chain PUFA. Aquaculture 2011, 312, 162-171. 
28. Van den Berg, M.; Birnbaum, L.; Denison, M.; de Vito, M.; Farland, W.; Feeley, F.; Fiedler, H.; Hakansson, H.; Hanberg, A.; Haws, L.; et al. The 2005 World Health Organization re-evaluation of human and mammalian toxic equivalency factors for dioxins and dioxin-like compounds. Toxicol. Sci. 2006, 93, 223-241.

29. Health Canada. Federal Contaminated Site Risk Assessment in Canada Part II: Health Canada Toxicological Reference Values (TRVs). Available online: http://publications.gc.ca/collections/ collection_2012/sc-hc/H128-1-11-638-eng.pdf (Accessed on 4 May, 2014).

30. Man Chan, H.; Yeboah, F. Total toxaphene and specific congeners in fish from the Yukon, Canada. Chemosphere 2000, 41, 507-515.

31. International Programme on Chemical Safety (IPCS), World Health Organization. Hexachlorobenzene. Available online: http://www.inchem.org/documents/ehc/ehc/ehc195.htm (Accessed on 4 May, 2014).

32. Bengtson Nash, S.M.; Waugh, C.A.; Schlabach, M. Metabolic concentration of Lipid Soluble Organochlorine Burdens in Humpback Whales Through Migration and Fasting. Environ. Sci. Technol. 2013, 47, 9404-9413.

33. Waugh, C.A.; Nichols, P.D.; Schlabach, M.; Noad, M.; Bengtson Nash, S.M. Vertical distribution of lipids, fatty acids and organochlorine contaminants in the blubber of southern hemisphere humpback whales (Megaptera novaeangliae). Mar. Environ. Res. 2014, 94, 24-31.

34. Poulsen, A.H.; Kawaguchi, S.; Landrum, P.; Bengtson Nash, S.M. Dietary exposure of Antarctic Krill to p,p'-DDE; uptake kinetics and toxicological sensitivity in a key polar species. Environ. Pollut. 2013, 175, 92-99.

35. Poulsen, A.H.; Kawaguchi, S.; Kukkonen, J.V.K.; Leppanen, M.; Bengtson Nash, S.M. Aqueous uptake and sublethal toxicity of p,p'-DDE in non-feeding larval stages of Antarctic krill (Euphausia superba). Environ. Pollut. 2012, 160, 185-191.

36. Poulsen, A.H.; Kawaguchi, S.; Kukkonen, J.V.K.; Leppanen, M.; Bengtson Nash, S.M. Altered developmental timing in early life stages of Antarctic krill (Euphausia superba) exposed to p,p'-DDE. Sci. Total Environ. 2011, 409, 5268-5276.

37. Poulsen, A.H.; Kawaguchi, S.; King, C.; King, R.A.; Bengtson Nash, S.M. Behavioural sensitivity of a key Southern Ocean species (Antarctic krill, Euphausia superba) to p,p'-DDE exposure. Ecotoxicol. Environ. Saf. 2012, 75, 163-170.

38. Barber, J.L.; Sweetman, A.J.; van Wijk, D.; Jones, K.C. Hexachlorobenzene in the global environment: Emissions, levels, distribution, trends and processes. Sci. Total Environ. 2005, 349, $1-44$.

39. Usydus, Z.; Szlinder-Richert, J.; Polak-Juszczak, L.; Malesa-Ciecwierz, M.; Dobrzanski, Z. Study on raw fish oil purification from PCDD/F and dl-PCB-industrial tests. Chemosphere 2009, 74, 1495-1501.

40. Maes, J.; de Meulenauer, B.; van Heerswynghels, P.; de Grey, W.; Eppe, G.; de Pauw, E.; Huyghebaert, A. Removal of dioxins and PCB from fish oil by activated carbon and its influence on the nutritional quality of the oil. J. Am. Oil Chem. Assoc. 2005, 82, 593-597.

(C) 2014 by the authors; licensee MDPI, Basel, Switzerland. This article is an open access article distributed under the terms and conditions of the Creative Commons Attribution license (http://creativecommons.org/licenses/by/3.0/). 